\title{
Dynamics Analysis for Hydroturbine Regulating System Based on Matrix Model
}

\author{
Jiafu Wei, ${ }^{1}$ Hao Wang, ${ }^{2}$ Yuanchu Cheng, ${ }^{2}$ and Xinran Guo ${ }^{2}$ \\ ${ }^{1}$ State Grid Hunan Electric Power Corporation Research Institute, Changsha 410007, China \\ ${ }^{2}$ School of Power and Mechanical Engineering, Wuhan University, Wuhan 430072, China \\ Correspondence should be addressed to Hao Wang; 1732208119@qq.com
}

Received 21 February 2017; Revised 31 May 2017; Accepted 4 June 2017; Published 6 July 2017

Academic Editor: Alessandro Arsie

Copyright (C) 2017 Jiafu Wei et al. This is an open access article distributed under the Creative Commons Attribution License, which permits unrestricted use, distribution, and reproduction in any medium, provided the original work is properly cited.

\begin{abstract}
The hydraulic turbine model is the key factor which affects the analysis precision of the hydraulic turbine governing system. This paper discusses the basic principle of the hydraulic turbine matrix model and gives two methods to realize. Using the characteristic matrix to describe unit flow and torque and their relationship with the opening and unit speed, it can accurately represent the nonlinear characteristics of the turbine, effectively improve the convergence of simulation process, and meet the needs of high precision real-time simulation of power system. Through the simulation of a number of power stations, it indicates that, by analyzing the dynamic process of the hydraulic turbine regulating with 5-order matrix model, the calculation results and field test data will have good consistency, and it can better meet the needs of power system dynamic simulation.
\end{abstract}

\section{Introduction}

As an important part of power system operation, the accuracy of the model is of great significance to the stability analysis of power system $[1,2]$. In the simulation of power system, the mathematical model of hydraulic turbine and governing system is often simplified to improve the calculation speed $[3,4]$, such as the use of linear model. The calculation error caused by the simplified model of the hydraulic system can be accepted for studying some problems, but not for the research for the long-term dynamic stability simulation of hydropower system, the stable simulation of fluctuation of surge shaft, the startup of turbine generator or sudden load rejection, and hydraulic-machine-electric coupling process simulation, and control and regulation problem into saturation and other nonlinear state; because of the incomplete data and the influence of the nonlinear conditions, the accuracy and reliability of the calculation are seriously affected, and it will even produce the unreasonable conclusions.

Therefore, it is necessary to analyze and study the mathematical model of hydraulic turbine governing system. In order to describe the nonlinear characteristics of hydraulic turbine, a simplified nonlinear model is proposed by IEEE. In this model, the turbine is simplified as a valve. Considering the influence of the rigid water hammer and the no-load flow on the turbine model, a simplified analytical model of nonlinear hydroturbine was obtained $[5,6]$. This model has good accuracy in the case of small fluctuations, and the model has been widely used in the United States' western Power Consortium [7, 8]. In article [9], an improved nonlinear model of turbine is derived based on the generalized basic equation of hydraulic turbine; the model is in good agreement with the actual data when analyzing the transient stability and damping of power system. Chang presented a hydraulic turbine model based on internal characteristics of turbine [10]. According to the specific parameters of the hydraulic turbine generator unit and the geometric structure and the movement rule of the control mechanism, the mathematical formula is deduced, and it has definite physical meaning. The simulation using the internal characteristic model has high accuracy with the actual data in the large opening, but it is difficult to measure the parameters of the hydraulic turbine structure [11]. The other methods are to deal with the comprehensive characteristic curve. Article [12] used the two-order differential equation model to describe the turbine system and used the least squares method to identify the parameters and orthogonal surface to fit the characteristics of hydraulic turbine. Good results are obtained in the case 
TABLE 1: Unit flow and unit torque table.

\begin{tabular}{lcccc}
\hline$\alpha$ & $\left(x_{11}\right)_{1}$ & $\left(x_{11}\right)_{2}$ & $\cdots$ & $\left(x_{11}\right)_{n}$ \\
\hline$\alpha_{1}$ & $\left(m_{11}\right)_{11}$ & $\left(m_{11}\right)_{12}$ & $\cdots$ & $\left(m_{11}\right)_{1 n}$ \\
$\alpha_{2}$ & $\left(m_{11}\right)_{21}$ & $\left(m_{11}\right)_{21}$ & $\cdots$ & $\left(m_{11}\right)_{2 n}$ \\
$\vdots$ & $\vdots$ & $\vdots$ & $\cdots$ & $\vdots$ \\
$\alpha_{n}$ & $\left(m_{11}\right)_{n 1}$ & $\left(m_{11}\right)_{n 2}$ & $\cdots$ & $\left(m_{11}\right)_{n n}$ \\
$\alpha_{1}$ & $\left(q_{11}\right)_{11}$ & $\left(q_{11}\right)_{12}$ & $\cdots$ & $\left(q_{11}\right)_{1 n}$ \\
$\alpha_{2}$ & $\left(q_{11}\right)_{21}$ & $\left(q_{11}\right)_{21}$ & $\cdots$ & $\left(q_{11}\right)_{2 n}$ \\
$\vdots$ & $\vdots$ & $\vdots$ & $\cdots$ & $\vdots$ \\
$\alpha_{n}$ & $\left(q_{11}\right)_{n 1}$ & $\left(q_{11}\right)_{n 2}$ & $\cdots$ & $\left(q_{11}\right)_{n n}$ \\
\hline
\end{tabular}

of small fluctuations. The BP neural network is used to model the characteristics of the turbine, which improves the convergence of water hammer calculation $[13,14]$. However, the commonly used method in the project is still the tabular interpolation of the comprehensive characteristic curve of the turbine $[15,16]$, while the common interpolation of twodimensional table will cause derivative's discontinuity in the whole domain, which leads to increased number of iterations or even no convergence.

In order to make up for the deficiency of the numerical table interpolation method in the calculation of turbine characteristic parameters, in this paper, the characteristics matrix is used to model the turbine, and the practical results of several projects are given.

\section{Modeling Principle of Characteristic Matrix Method}

For the convenience of calculation and discussion, it is assumed that the unit flow rate and the unit torque table of a certain type of turbine have been obtained, as shown in Table 1. The data in the table represents the condition of $n$ equal opening lines and $n$ unit speeds, where $\alpha$ is the opening, $m_{11}$ is unit torque, $q_{11}$ is unit discharge, and $x_{11}$ is the unit speed of the point. By observing the data in Table 1 and combining with the characteristic curve of turbine, under a given opening $\alpha$, this paper can use $n-1$-order polynomial to represent the unit discharge and the unit torque. For example, unit flow can be expressed as follows:

$$
\begin{aligned}
q_{11} & =A_{1}+A_{2} x+\cdots+A_{n} x^{n-1} \\
& =\left[\begin{array}{llll}
A_{1} & A_{2} & \cdots & A_{n}
\end{array}\right]\left[\begin{array}{c}
1 \\
x \\
\vdots \\
x^{n-1}
\end{array}\right] .
\end{aligned}
$$

It is obvious that the polynomial coefficients about the unit speed are the function of the opening $\alpha$. The specific form is shown as follows:

$$
\begin{gathered}
A_{1}=a_{11}+a_{21} \alpha+a_{31} \alpha^{2}+\cdots+a_{n 1} \alpha^{n-1} \\
A_{2}=a_{12}+a_{22} \alpha+a_{32} \alpha^{2}+\cdots+a_{n 2} \alpha^{n-1} \\
\vdots \\
A_{n}=a_{1 n}+a_{2 n} \alpha+a_{3 n} \alpha^{2}+\cdots+a_{n n} \alpha^{n-1} .
\end{gathered}
$$

For an opening, the coefficients can be expressed in matrix form:

$$
\begin{aligned}
{\left[\begin{array}{c}
A_{1} \\
A_{2} \\
\vdots \\
A_{n}
\end{array}\right]_{i}=\left[\begin{array}{cccc}
a_{11} & a_{21} & \cdots & a_{n 1} \\
a_{12} & a_{22} & \cdots & a_{n 2} \\
\vdots & \vdots & \vdots & \vdots \\
a_{1 n} & a_{2 n} & \cdots & a_{n n}
\end{array}\right]\left[\begin{array}{c}
1 \\
\alpha_{i} \\
\vdots \\
\alpha_{i}{ }^{n-1}
\end{array}\right], } \\
{\left[\begin{array}{llll}
A_{1} & A_{2} & \cdots & A_{n}
\end{array}\right]_{i}=\left[\begin{array}{c}
1 \\
\alpha_{i} \\
\vdots \\
\alpha_{i}^{n-1}
\end{array}\right]^{T}\left[\begin{array}{cccc}
a_{11} & a_{21} & \cdots & a_{n 1} \\
a_{12} & a_{22} & \cdots & a_{n 2} \\
\vdots & \vdots & \vdots & \vdots \\
a_{1 n} & a_{2 n} & \cdots & a_{n n}
\end{array}\right], }
\end{aligned}
$$

Combining formulas (1) to (3), one has

$$
q_{11}=\left[\begin{array}{c}
1 \\
\alpha_{i} \\
\vdots \\
\alpha_{i}^{n-1}
\end{array}\right]^{T}\left[\begin{array}{cccc}
a_{11} & a_{21} & \cdots & a_{n 1} \\
a_{12} & a_{22} & \cdots & a_{n 2} \\
\vdots & \vdots & \vdots & \vdots \\
a_{1 n} & a_{2 n} & \cdots & a_{n n}
\end{array}\right]^{T}\left[\begin{array}{c}
1 \\
x \\
\vdots \\
x^{n-1}
\end{array}\right] \text {. }
$$

For the convenience of presentation, use the following expressions:

$$
\begin{aligned}
\left\{x_{i j}\right\}_{n \times n} & =\left[\begin{array}{cccc}
1 & 1 & \cdots & 1 \\
\left(x_{11}\right)_{1} & \left(x_{11}\right)_{2} & \cdots & \left(x_{11}\right)_{n} \\
\vdots & \vdots & \cdots & \vdots \\
\left(x_{11}\right)_{1}^{n-1} & \left(x_{11}\right)_{2}^{n-1} & \cdots & \left(x_{11}\right)_{n}^{n-1}
\end{array}\right] \\
\left\{\alpha_{i j}\right\}_{n \times n} & =\left[\begin{array}{cccc}
1 & \alpha_{1} & \cdots & \alpha_{1}^{n-1} \\
1 & \alpha_{2} & \cdots & \alpha_{2}^{n-1} \\
\vdots & \vdots & \cdots & \vdots \\
1 & \alpha_{n} & \cdots & \alpha_{n}^{n-1}
\end{array}\right]
\end{aligned}
$$




$$
\left\{\left(a_{q}\right)_{i j}\right\}_{n \times n}=\left[\begin{array}{cccc}
a_{11} & a_{21} & \cdots & a_{n 1} \\
a_{12} & a_{22} & \cdots & a_{n 2} \\
\vdots & \vdots & \vdots & \vdots \\
a_{1 n} & a_{2 n} & \cdots & a_{n n}
\end{array}\right]^{T} .
$$

According to (4), one can get

$$
\left\{\left(q_{11}\right)_{i j}\right\}_{n \times n}=\left\{\alpha_{i j}\right\}_{n \times n}\left\{\left(a_{q}\right)_{i j}\right\}_{n \times n}\left\{\left(x_{11}\right)_{i j}\right\}_{n \times n} .
$$

For unit torque, the same can be obtained:

$$
\left\{\left(m_{11}\right)_{i j}\right\}_{n \times n}=\left\{\alpha_{i j}\right\}_{n \times n}\left\{\left(a_{m}\right)_{i j}\right\}_{n \times n}\left\{\left(x_{11}\right)_{i j}\right\}_{n \times n} .
$$

The matrix $\left\{\left(a_{q}\right)_{i j}\right\}_{n \times n}$ and $\left\{\left(a_{m}\right)_{i j}\right\}_{n \times n}$ is defined as the characteristic matrix of the unit flow rate and unit torque of turbine. The characteristic matrix terms in (6) and (7) can be calculated from the unit flow table and the unit torque table of the turbine curves. So the turbine characteristic matrix can be concluded by formulas (8) and (9).

$$
\begin{aligned}
\left\{\left(a_{q}\right)_{i j}\right\} & =\left\{a_{i j}\right\}^{-1}\left\{\left(a_{11}\right)_{i j}\right\}\left\{\left(x_{11}\right)_{i j}\right\}^{-1} \\
\left\{\left(a_{m}\right)_{i j}\right\} & =\left\{a_{i j}\right\}^{-1}\left\{\left(m_{11}\right)_{i j}\right\}\left\{\left(x_{11}\right)_{i j}\right\}^{-1} \\
x_{11} & =\frac{n D}{\sqrt{H}} .
\end{aligned}
$$

$n$ is speed, $D$ represents the diameter of the runner, and $H$ is current head. Through calculating the characteristic matrix, a matrix model of the hydroturbine is got.

At a certain time, according to turbine head $H$ and speed $n$, the unit speed $x_{11 t}$ can be calculated with (10); then combining the current guide vane opening, the unit flow rate and unit torque at any time can be quickly obtained by calculating the turbine characteristic parameters with characteristic matrix.

$$
\begin{gathered}
q_{11 t}=\left(1, \alpha_{t}, \alpha_{t}^{2}, \ldots, \alpha_{t}^{n-1}\right)\left\{\left(a_{q}\right)_{i j}\right\}\left[\begin{array}{c}
1 \\
\left(x_{11 t}\right) \\
\vdots \\
\left(x_{11 t}\right)^{n-1}
\end{array}\right] \\
m_{11 t}=\left(1, \alpha_{t}, \alpha_{t}^{2}, \ldots, \alpha_{t}^{n-1}\right)\left\{\left(a_{m}\right)_{i j}\right\}\left[\begin{array}{c}
1 \\
\left(x_{11 t}\right) \\
\vdots \\
\left(x_{11 t}\right)^{n-1}
\end{array}\right] .
\end{gathered}
$$

The above method can be used to solve the flow and torque at any time, but, in the calculation of the characteristic matrix, the method of selecting the points from the unit flow and torque table is limited. It can only obtain $n$ opening and $n$ unit speed and $n \times n$ corresponding points of unit flow rate and unit torque as the input of the arithmetic. In order to improve the flexibility of access points, the method is improved by taking formula (2) directly into formula (1). A matrix equation of $(n \times n) \times(n \times n)$ is needed to obtain all the coefficients. Then the solution of each element of the characteristic matrix is seen in the following formula:

$\left[\begin{array}{c}a_{11} \\ a_{21} \\ \vdots \\ a_{n \times n}\end{array}\right]$

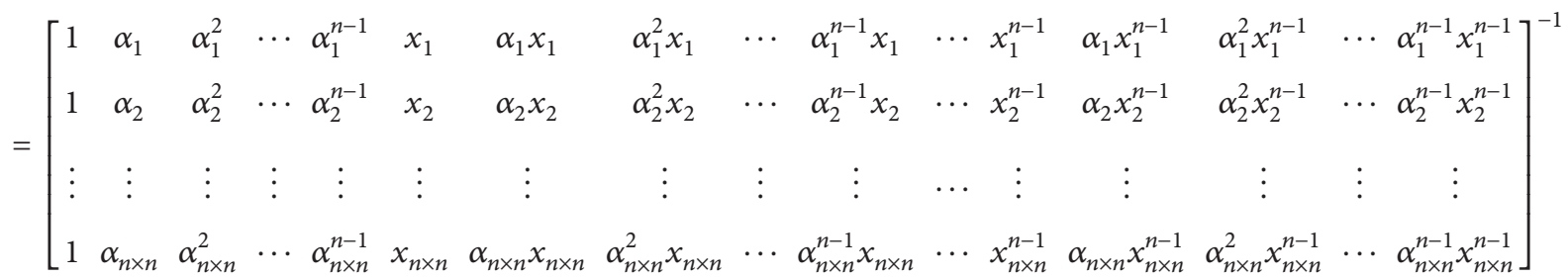

$$
\left[\begin{array}{c}
q_{1} \\
q_{2} \\
\vdots \\
q_{n \times n}
\end{array}\right]
$$


Accordingly, this paper can use the same method to solve the characteristic matrix of unit torque. Using the improved method to solve the feature matrix can remove the restriction of the point selection. The required characteristic matrix can be calculated as long as the points are linearly independent.

$$
\begin{aligned}
& {\left[\begin{array}{c}
a_{11} \\
a_{21} \\
\vdots \\
a_{n \times n}
\end{array}\right]} \\
& =\left[\begin{array}{cccccccc}
1 & \alpha_{1} & \alpha_{1}^{2} & \cdots & \alpha_{1}^{n-1} & x_{1} & \alpha_{1} x_{1} & \alpha_{1}^{2} x_{1} \\
1 & \alpha_{2} & \alpha_{2}^{2} & \cdots & \alpha_{2}^{n-1} & x_{2} & \alpha_{2} x_{2} & \alpha_{2}^{2} x_{2} \\
\vdots & \vdots & \vdots & \vdots & \vdots & \vdots & \vdots & \vdots \\
1 & \alpha_{n \times n} & \alpha_{n \times n}^{2} & \cdots & \alpha_{n \times n}^{n-1} & x_{n \times n} & \alpha_{n \times n} x_{n \times n} & \alpha_{n \times n}^{2} x_{n \times n} \\
m_{1} \\
m_{2} \\
\vdots \\
m_{n \times n}
\end{array}\right] . \\
& \text { 3. Case Study with 5-Order Matrix Model of } \\
& \text { Hydraulic Turbine }
\end{aligned}
$$

\section{Case Study with 5-Order Matrix Model of Hydraulic Turbine}$$
=\left[\begin{array}{cccccccccccccccc}
1 & \alpha_{1} & \alpha_{1}^{2} & \cdots & \alpha_{1}^{n-1} & x_{1} & \alpha_{1} x_{1} & \alpha_{1}^{2} x_{1} & \cdots & \alpha_{1}^{n-1} x_{1} & \cdots & x_{1}^{n-1} & \alpha_{1} x_{1}^{n-1} & \alpha_{1}^{2} x_{1}^{n-1} & \cdots & \alpha_{1}^{n-1} x_{1}^{n-1} \\
1 & \alpha_{2} & \alpha_{2}^{2} & \cdots & \alpha_{2}^{n-1} & x_{2} & \alpha_{2} x_{2} & \alpha_{2}^{2} x_{2} & \cdots & \alpha_{2}^{n-1} x_{2} & \cdots & x_{2}^{n-1} & \alpha_{2} x_{2}^{n-1} & \alpha_{2}^{2} x_{2}^{n-1} & \cdots & \alpha_{2}^{n-1} x_{2}^{n-1} \\
\vdots & \vdots & \vdots & \vdots & \vdots & \vdots & \vdots & \vdots & \vdots & \vdots & \cdots & \vdots & \vdots & \vdots & \vdots & \vdots \\
1 & \alpha_{n \times n} & \alpha_{n \times n}^{2} & \cdots & \alpha_{n \times n}^{n-1} & x_{n \times n} & \alpha_{n \times n} x_{n \times n} & \alpha_{n \times n}^{2} x_{n \times n} & \cdots & \alpha_{n \times n}^{n-1} x_{n \times n} & \cdots & x_{n \times n}^{n-1} & \alpha_{n \times n} x_{n \times n}^{n-1} & \alpha_{n \times n}^{2} x_{n \times n}^{n-1} & \cdots & \alpha_{n \times n}^{n-1} x_{n \times n}^{n-1}
\end{array}\right]^{n-1}
$$

\subsection{Case 1}

3.1.1. The Model and Parameters. The main parameters of a hydropower station are as follows: rated head $H_{r}=216 \mathrm{~m}$, rated speed $n_{r}=150 \mathrm{r} / \mathrm{min}$, rated flow $Q_{r}=360.3 \mathrm{~m}^{3} / \mathrm{s}$, rated power $P_{r}=714 \mathrm{MW}$, the maximum of the opening $a_{\text {max }}=28.5 \mathrm{~mm}$ (model), head loss coefficients are 0.0098 and $8.402 \times 10^{-4}$, and their water flow inertia time constants are $1.3 \mathrm{~s}$ and $0.65 \mathrm{~s}$, respectively. The time constant of the surge tank $T_{j}=482 \mathrm{~s}$; impedance hole loss coefficient $f_{0}=$ 0.0049 . The governor adopts the parallel PID microcomputer governor which is consistent with the actual governor control law and structure; the simulation model is shown in Figure 1. The parameters are set according to the actual governor parameters, permanent speed droop $b p=0.04$, proportional gain $\mathrm{Kp}=4.5$, integral gain $\mathrm{Ki}=0.1$, differential gain $\mathrm{Kd}=$ 2 , differential time constant $\mathrm{Tn}=0.2$, and servomotor time constant Ty $=6.39$.

The mathematical model of the generator uses 1-order model; the transfer function is

$$
G_{S}(S)=\frac{1}{T_{a} S+e_{g}} .
$$

In the formula, $T_{a}$ is the unit inertia time constant; $e_{g}$ is the generator load self-regulation coefficient.

3.1.2. Simulation Results and Analysis. Simulation step is $0.01 \mathrm{~s}$ and $H=164 \mathrm{~m}$. The simulation was carried out in small and large disturbance with 5-order matrix model of hydraulic turbine and IEEE proposed turbine model. When the disturbance is small, the frequency change process is more consistent, but the absolute position of the servomotor is not the same. Then the simulations for $25 \%$ and $50 \%$ load rejection results are shown in Figures 2 and 3. The solid lines indicate simulation results of 5-order turbine matrix model and the dashed line represents simulation results using IEEE recommendation model. The blue lines are the prototype test results. The simulation results in Tables 2 and 3 show that when the disturbance is large, the simulation results of the two models are quite different. First, the maximum frequency of 5-order matrix and prototype is obviously different with IEEE proposed turbine model. Besides, the simulation results using 5-order turbine matrix model coincide better with the prototype test results in the law of gate opening movement.

3.2. Case 2. The main parameters of a hydropower station are as follows: rated head $H_{r}=73 \mathrm{~m}$, rated speed $n_{r}=150 \mathrm{r} / \mathrm{min}$, rated flow $Q_{r}=180.2 \mathrm{~m}^{3} / \mathrm{s}$, rated power $P_{r}=115 \mathrm{MW}$, actual operating head $H=71.5 \mathrm{~m}$, the maximum of the opening $a_{\max }=34 \mathrm{~mm}$ (model), and water flow inertia time constant $T_{w}=1.47 \mathrm{~s}$. The governor model adopts the parallel PID microcomputer governor which is consistent with the actual governor control law and structure.

Initial condition is $H=73 \mathrm{~m}$ and $P=90 \mathrm{MW}$, with large net mode; the frequency disturbance is $\pm 0.2 \mathrm{HZ}$.

Using the characteristic matrix to establish the 5-order hydroturbine matrix model, the simulation result of primary frequency regulation is shown in Figure 4. The black line indicates the power of the prototype experiment result, and 


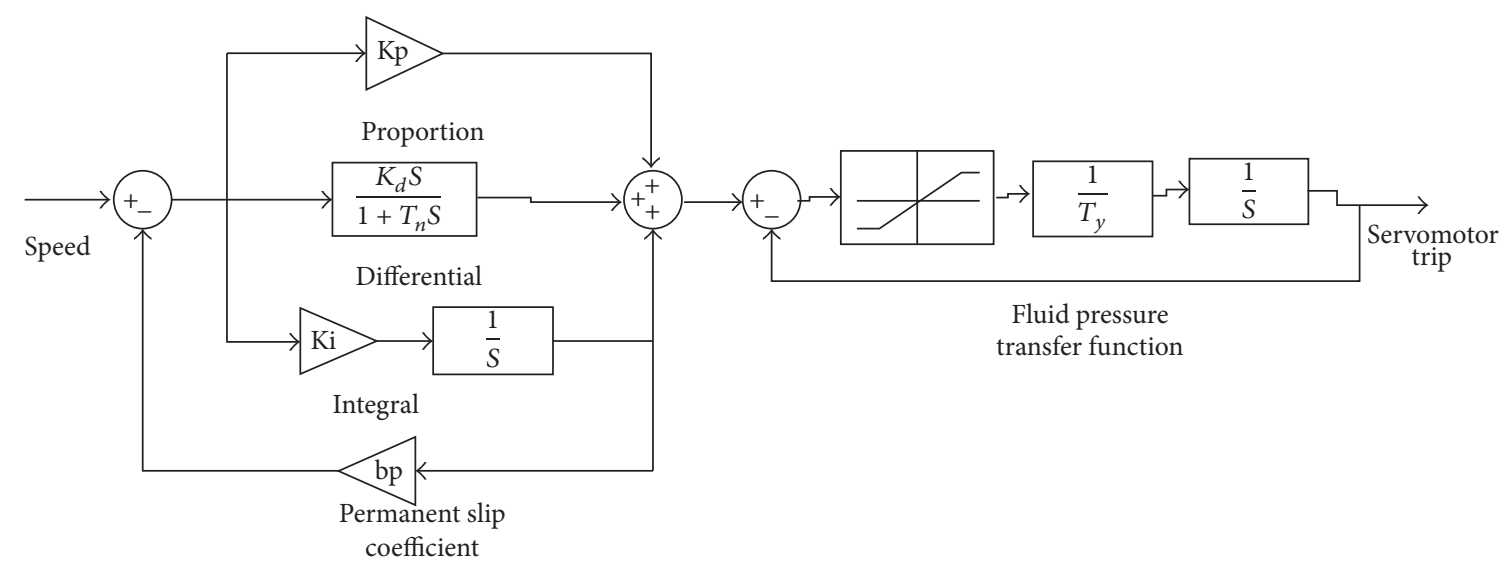

FIgURE 1: The simulation model of governor.
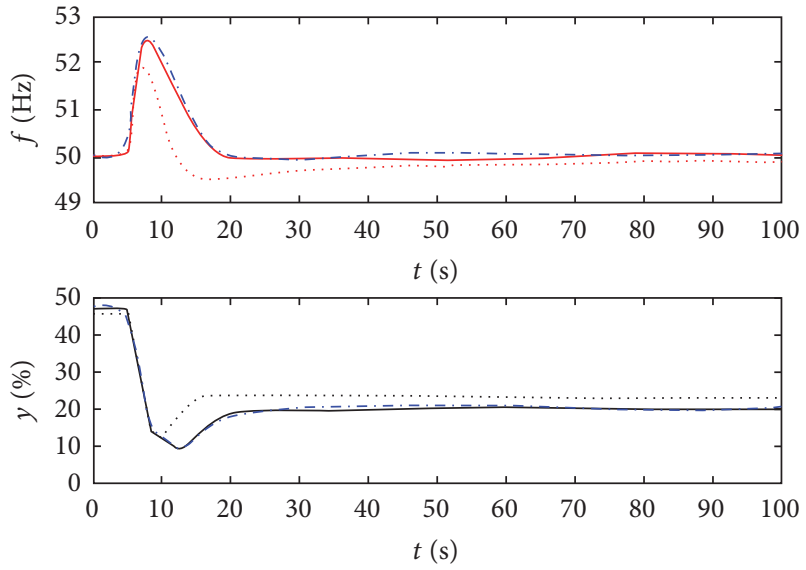

FIGURE 2: Simulation comparison of $25 \%$ load rejection.
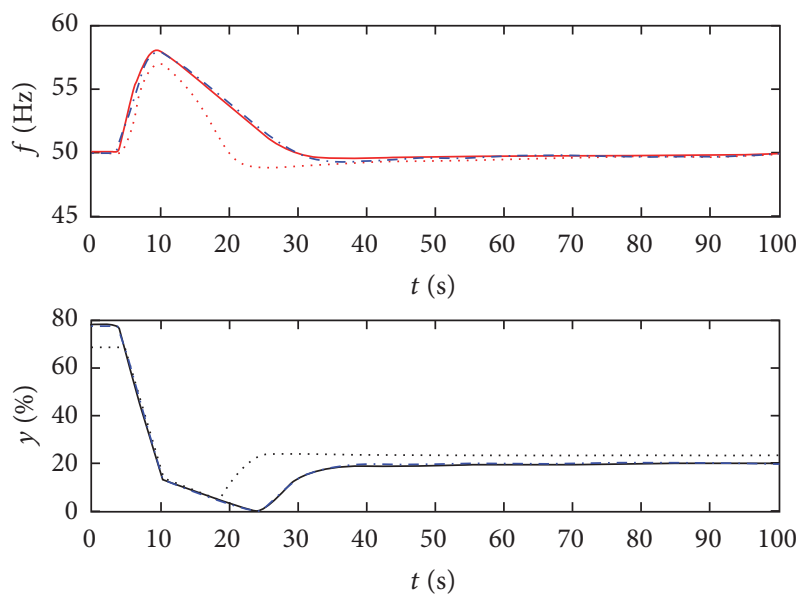

FIGURE 3: Simulation comparison of 50\% load rejection.

the blue line represents the simulation power according to the law of gate opening of the prototype.

Then load regulation test is also simulated, the initial condition is $H=71.5 \mathrm{~m}$ and $P=115 \mathrm{MW}$, with large net

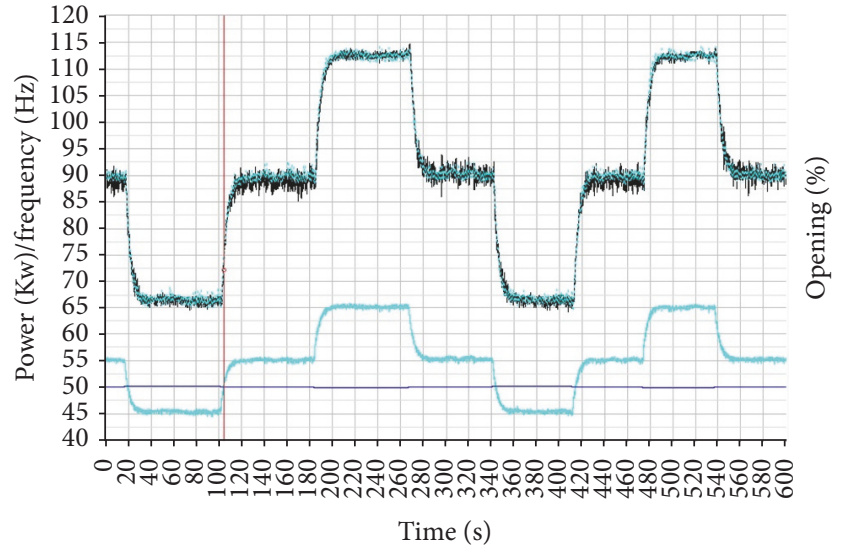

FIgURE 4: The power output using prototype and 5-order matrix models in primary frequency regulation mode after frequency disturbance.

TABLE 2: The result of $25 \%$ load rejection.

\begin{tabular}{lccc}
\hline Variable & 5-Order matrix & Prototype & IEEE \\
\hline Frequency maximum (Hz) & 52.50 & 52.51 & 51.96 \\
Time of maximum frequency (s) & 9.21 & 9.25 & 7.62 \\
Frequency minimum (Hz) & 49.99 & 49.98 & 49.52 \\
Time of minimum frequency (s) & 20.82 & 21.03 & 15.73 \\
Time of stabilization (s) & 42.13 & 41.35 & 48.23 \\
Time of servomotor reversing (s) & 13.22 & 13.24 & 10.09 \\
\hline
\end{tabular}

TABLE 3: The result of $50 \%$ load rejection.

\begin{tabular}{lccc}
\hline Variable & 5-Order matrix & Prototype & IEEE \\
\hline Frequency maximum $(\mathrm{Hz})$ & 58.20 & 58.18 & 57.12 \\
Time of maximum frequency (s) & 9.98 & 10.01 & 10.02 \\
Frequency minimum (Hz) & 49.98 & 49.96 & 48.85 \\
Time of minimum frequency (s) & 37.83 & 37.80 & 23.72 \\
Time of stabilization (s) & 46.85 & 47.32 & 51.24 \\
Time of servomotor reversing (s) & 24.78 & 24.76 & 18.54 \\
\hline
\end{tabular}




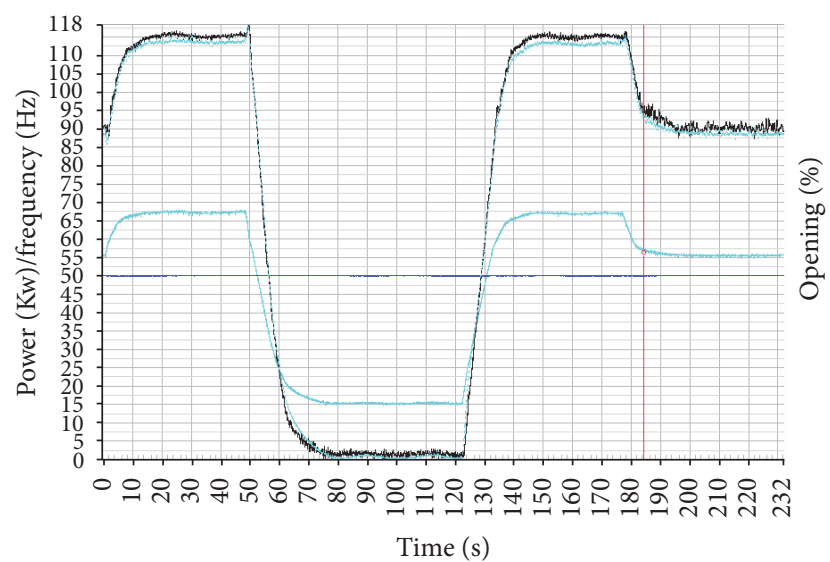

FIGURE 5: The power regulation using prototype and 5-order matrix models in large net.

mode, and the range of load regulation is $0 \sim 100 \%$; the result of simulation is shown in Figure 5.

From the cases, the 5-order matrix model has similar transition process and steady-state value to the prototype. So the 5-order matrix model can also coincide well with the prototype in the condition of the primary frequency modulation.

\section{Conclusion}

The characteristic of the hydraulic turbine has a strong nonlinearity with the change of the operating conditions. In this paper, the turbine characteristic is modeled with 5-order matrix, and the detailed calculation method is given. The simulation indicates that the method can represent the strong nonlinearity of turbine and has better convergence and fast calculation speed. The calculated result is well identical to the results of prototype experiment. So the model can be used in the calculation of the transient process of the hydraulic turbine governing system and the dynamic simulation of the power system. It can meet the needs of power system dynamic simulation and stability analysis better.

\section{Conflicts of Interest}

The authors declare that there are no conflicts of interest regarding the publication of this paper.

\section{References}

[1] J. L. Aguero, P. L. Arnera, M. B. Barbieri et al., "Hydraulic transients in hydropower plant impact on power system dynamic stability," in Proceedings of the Energy Society General Meeting, pp. 1-6, Pittsburgh, PA, USA, 2008.

[2] N. Kishor, R. P. Saini, and S. P. Singh, "A review on hydropower plant models and control," Renewable and Sustainable Energy Reviews, vol. 11, no. 5, pp. 776-796, 2007.

[3] C. D. Vournas and G. Papaioannou, "Modelling and stability of a hydro plant with two surge tanks," IEEE Transactions on Energy Conversion, vol. 10, no. 2, pp. 368-375, 1995.
[4] A. Izena, H. Kihara, T. Shimojo et al., "Practical hydraulic turbine model," in Proceedings of the 2006 IEEE Power Engineering Society General Meeting, PES, Quebec, Canada, 2006.

[5] P. Kunder, N. J. Balu, and M. G. Lauby, Power System Stability and Control, McGraw-Hill, New York, NY, USA, 1994.

[6] F. Demello, R. Koessler, J. Agee et al., "Hydraulic turbine and turbine control models for system dynamic studies," IEEE Transactions on Power Systems, vol. 7, no. 1, pp. 167-179, 1992.

[7] S. Patterson, "Importance of hydro generation response resulting from the new thermal modeling and required hydro modeling improvements," in Proceedings of the IEEE Power Engineering Society General Meeting, pp. 1779-1783, Denver, Colo, USA, 2004.

[8] D. N. Kosterev, "Hydro turbine-governor model validation in pacific northwest," IEEE Transactions on Power Systems, vol. 19, no. 2, pp. 1144-1149, 2004.

[9] X. Wang, X. Li, J. Liu, R. Huang, and L. Ding, "A modified nonlinear hydraulic turbine model and its impact on power system simulation," Power System Technology, vol. 38, no. 6, pp. 1606-1610, 2014.

[10] J. Chang, Transition Process of Hydraulic Machinery, Machinery Industry Press, Beijing, China, 1991.

[11] X. Xia, "Model parameter identification and fault diagnosis of hydro generator unit," 2015, Huazhong University of Science \& Technology.

[12] M. Yan and C. Zhang, "Hypersurface orthogonal polynomial least squares fitting of turbine characteristic," Large Motor Technology, vol. 4, pp. 60-63, 1986.

[13] Y. Cheng, "Neural network modeling of hydraulic turbine characteristics," Huazhong University of Science \& Technology, vol. 6, pp. 68-70, 2003.

[14] Z. Xiao, S. Wang, H. Zeng, and X. Yuan, "Identifying of hydraulic turbine generating unit model based on neural network," in Proceedings of the 6th International Conference on Intelligent Systems Design and Applications (ISDA '06), Jinan, China, 2006.

[15] S. Zuyi, The Hydraulic Turbine Regulation, China Water Conservancy and Hydropower Publishing House, Beijing, China, 1998.

[16] C. Yuanchu, "An improved parabola interpolation method for calculation of transient process of hydraulic turbine," Design of Hydropower Station, vol. 1, pp. 57-61, 1997. 


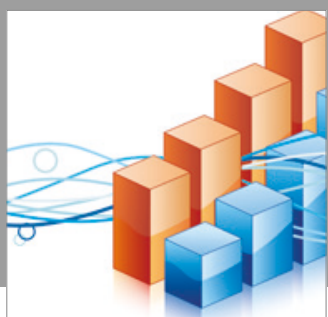

Advances in

Operations Research

vatersals

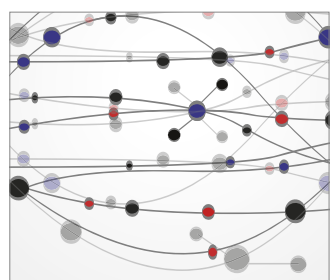

\section{The Scientific} World Journal
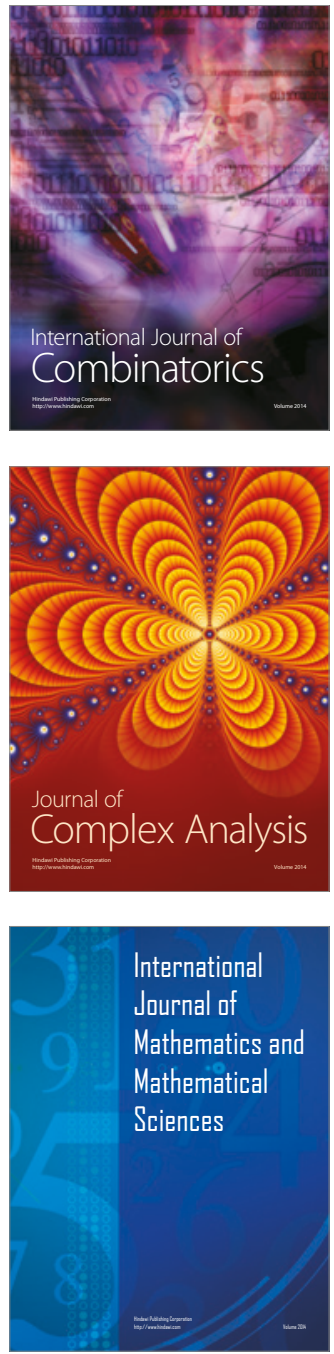
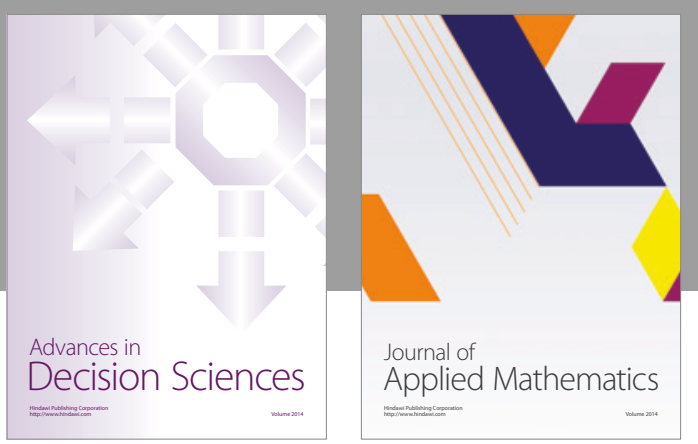

Algebra

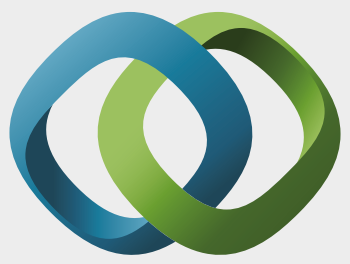

\section{Hindawi}

Submit your manuscripts at

https://www.hindawi.com
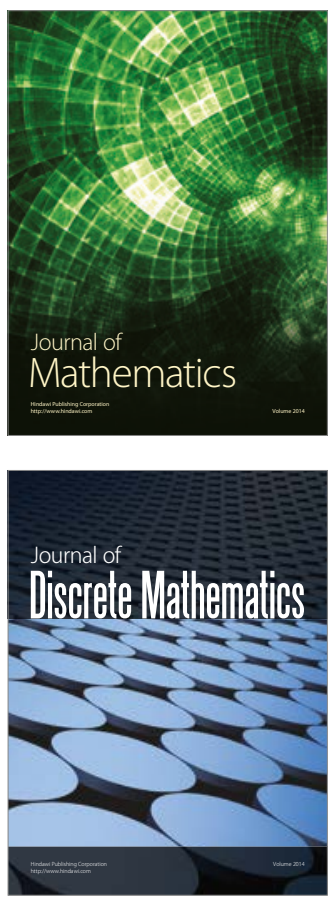

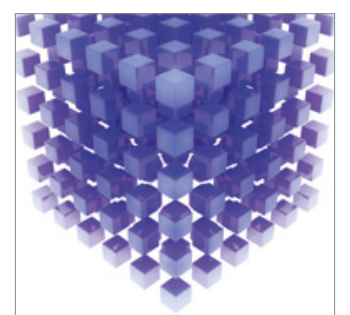

Mathematical Problems in Engineering
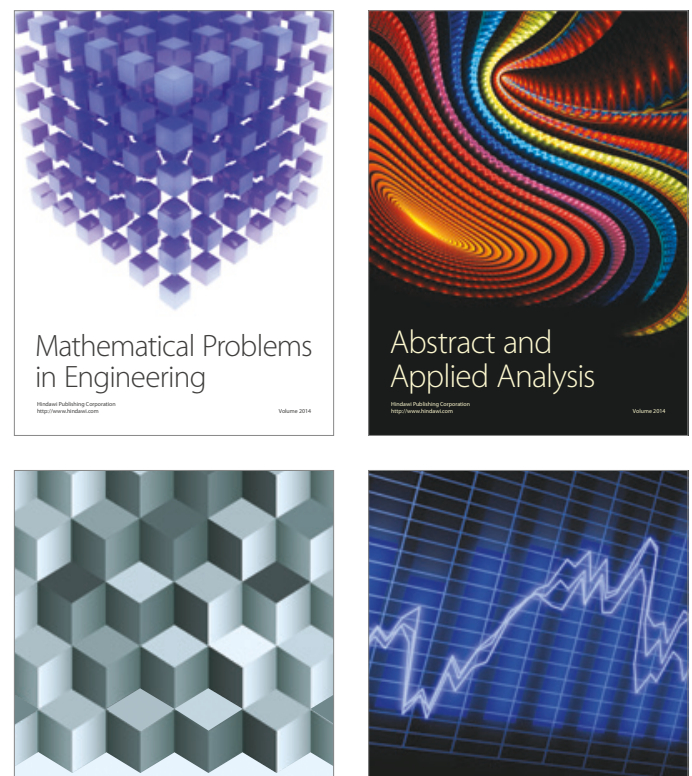

Journal of

Function Spaces

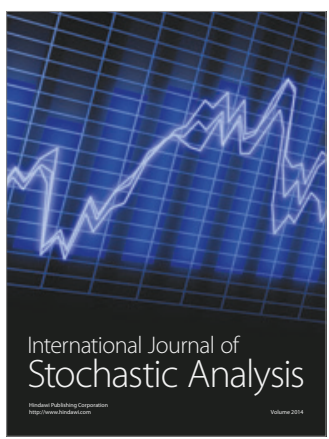

Probability and Statistics
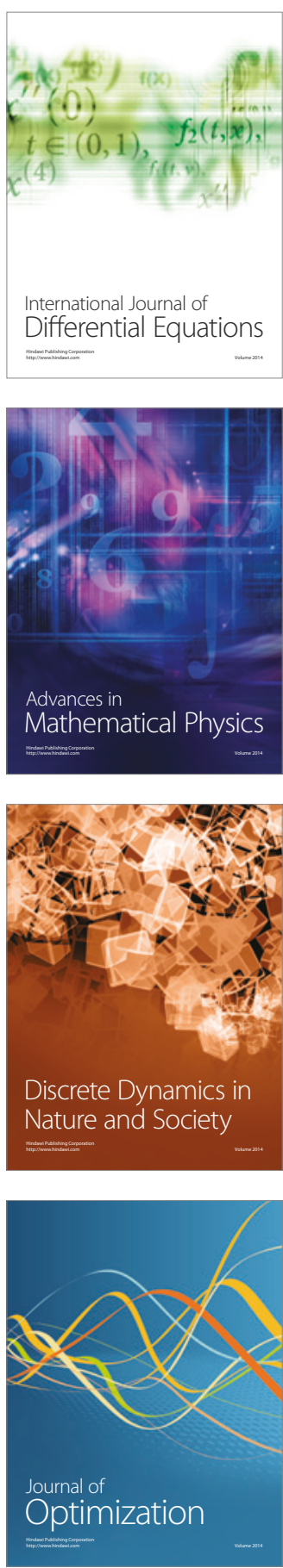